\title{
Tobacco Use and its Association with Gingivitis among Dental Students of Dow Dental College
}

\author{
Hina Toufique $^{1}$ BDS \\ Nighat Nisar ${ }^{2}$ \\ MBBS, MPH, FCPS \\ Sohail Saadat ${ }^{3}$ \\ BDS, MDS
}

\begin{abstract}
:
Background: In developing world, tobacco use among doctors and dentists is a major issue. The doctors and dentists are considered as advocates of health and responsible for providing guidance to the population. However, smoking among health professionals especially dentists has been linked with many oral health issues including gingivitis.

Objective: To determine the association of tobacco use with gingivitis among dental students of Dow Dental College, Karachi, Pakistan.

Methodology: This cross-sectional study was conducted among 150 dental students of Dow Dental College, Karachi, Pakistan. Participants were asked to fill a self administered questionnaire containing questions regarding smoking habits, knowledge related to hazards of smoking and socio-demographic characteristics. The questions related to smoking were adopted from the National Adult Tobacco Survey (NATS) by Centre for Disease Control (CDC). The participants were examined for the presence of gingivitis using Gingival Index by the principal investigator. The examination was done with patient on dental chair in out-patient department of Dow Dental College.

Results: The frequency of smoking was $92(61 \%)$ among dental students of Dow Dental College. Similarly the frequency of smokeless tobacco use was present in $30(20 \%)$ of individuals. The mean age of the students was $21.52 \pm 1.51$ years. Mean age of initiation of smoking was $16.88 \pm 4.01$ years. Gingival index score was significantly higher among smokers $1.25 \pm 0.91$ as compared to non-smokers $0.39 \pm 0.63$ (p-value $<0.001)$

Conclusion: This study found high frequency of smoking among dental students and the gingival index score was higher among smokers as compared to non-smokers.

KEYWORDS: Tobacco, Smoking, Gingivitis, Dental Students, Gingival Index.

HOW TO CITE: Toufique H, Nisar N, Saadat S. Tobacco Use and its Association with Gingivitis among Dental Students of Dow Dental College. J Pak Dent Assoc 2017; 26(2): 67-71
\end{abstract}

Received: 8 May 2017, Accepted: 3 June 2017

\section{INTRODUCTION}

$\mathrm{T}$ he devastating results of tobacco use on wellbeing and health have been very frequently reported. Various studies have affirmed the strong quantitative relationship between smoking and numerous illnesses, for example, coronary arteries blockage, lung tumours, bladder malignancies, emphysema, vascular

1. Lecturer / MDS Trainee, Department of Community Dentisry, Dow Dental College, Dow University of Health Sciences, Karachi, Pakistan

2. Professor and Head of Community Medicine, Dean School of Public

Health, Dow University of Health Sciences, Karachi, Pakistan

3. Assistant Professor, Dow International College, Dow University of Health Sciences, Karachi, Pakistan

Corresponding author: "Dr. Hina Toufique"

<dr.hina95@yahoo.com> disorders and neonatal morbidity ${ }^{1-3}$. In the developing part of the world, smoking is quite common and prevalent among doctors $^{1,4}$.

Smoking among doctors and dentists is problematic in two ways as doctors are the in charge of providing health guidance to general population and responsible for the future health and wellbeing of their nation, their behaviour of tobacco use can have adverse impacts on general population's behaviour ${ }^{5}$.

The prevalence of tobacco use is high in Pakistan and the trend of smoking was found similar to other developing countries $^{6}$. It is estimated that $36 \%$ of men and $9 \%$ of women use some form of tobacco on a regular basis. The mean age of onset for cigarette smoking in Pakistan is 18 years for males and 24 years for females. Inspite of more 
knowledge about its harmful effects cigarette smoking is widespread among the medical students around the world ${ }^{7}$.

It has been well established that younger the age of smoking onset, higher the dependence on smoking and more difficult it becomes to quit ${ }^{8,9}$. The Pakistani young medical and dental students who start smoking under peer pressure or social gatherings have less chances of quitting smoking and therefore not only harm their own lives but also set a bad example for their patients. A study conducted in 1993 among medical students of the Aga Khan University, Karachi, showed that $11 \%$ of the medical students were smokers (males $17 \%$, females $4 \%{ }^{10}$.

Another study conducted in Karachi reported that the prevalence of smoking was $14.4 \%$ among medical and dental students ${ }^{2}$. A study from a private medical college reported that the prevalence of smoking among male students was $26 \%$ and female students was $1.7 \%{ }^{7}$. Among medical and dental students who smoke cigarettes, gingivitis is one of the earliest findings ${ }^{4}$. In a study conducted in Saudi Arabian dental students, smoking was prevalent among 13\% of the students and $10 \%$ of them suffered from poor oral hygiene, gingivitis and other oral health disorders ${ }^{4}$.

This study is conducted to determine frequency of tobacco use either in the form of smoking or in its chewing smokeless form, among dental students and its association with gingivitis among dental students of Dow dental college of Karachi, Pakistan.

\section{OBJECTIVE}

To determine the association of tobacco use (both smoked and smokeless) with gingivitis among dental students of Dow Dental College, Karachi, Pakistan

\section{METHODOLOGY}

A cross-sectional study was conducted and 150 students of Dow Dental College were enrolled in the study by using convenience sampling. The sample size was calculated using online sample size calculator for frequency of tobacco use among medical students in Karachi as $14.4 \%$ reported by Khan et al. ${ }^{2}$, with margin of error at $6 \%$ and confidence level at $95 \%$, it was calculated to be 132 . After taking the consent the student were asked to fill a self administered questionnaire containing questions regarding smoking habits, and socio-demographic characteristics. The questions related to smoking was adopted from the National Adult Tobacco Survey (NATS) by Centre for Disease Control $(\mathrm{CDC})^{11}$. The students were examined for the presence of gingivitis using Gingival Index by the principal investigator.
The examination was done with patient on dental chair in the out-patient department of Dow Dental College.

The data were entered and analysed by using SPSS version 20. Frequency of smokers and non smokers were calculated and presence of gingivitis was calculated by using gingival index. The chi-square test was applied to determine association of smoking and gingivitis. The P-value of $\leq 0.05$ was considered statistically significant.

\section{RESULTS}

The frequency of smoking was found 92 (61\%) among dental students of Dow Dental College. The mean age of the students was21.52 \pm 1.51 years. Mean age of initiation of smoking was $16.88 \pm 4.01$ years. Fifty eight percent of smokers smoked daily and $75 \%$ were males.

Table 1. Socio-Demographic Factors of Dental Students

\begin{tabular}{|c|c|}
\hline Characteristics & $\begin{array}{l}\text { Frequency } \\
\mathrm{N}=150(\%)\end{array}$ \\
\hline \multicolumn{2}{|l|}{ Gender } \\
\hline Male & $113(75)$ \\
\hline Female & $37(25)$ \\
\hline \multicolumn{2}{|l|}{ Year of Education } \\
\hline First & $23(15)$ \\
\hline Second & $37(25)$ \\
\hline Third & $57(38)$ \\
\hline Fourth & $33(22)$ \\
\hline \multicolumn{2}{|l|}{ Tobacco Use } \\
\hline Yes & $92(61)$ \\
\hline No & $58(39)$ \\
\hline \multicolumn{2}{|l|}{ Smokeless Tobacco use } \\
\hline Yes & $30(20)$ \\
\hline No & $120(80)$ \\
\hline
\end{tabular}

No statistically significant difference was found when ages of male and female smokers were compared.

Majority of dental students smoked less than 10 cigarettes per day whereas $19 \%$ smoked more than 20 cigarettes per day. Further details of number of cigarettes consumed by dental students are shown in Table 3 . 
Table 2. Tobacco Use among Different Dental Students

\begin{tabular}{|c|c|c|c|c|}
\hline Characteristics & $\begin{array}{c}\text { Tobacco users } \\
\text { n(\%) }\end{array}$ & $\begin{array}{c}\text { Tobacco Non-users } \\
\text { n(\%) }\end{array}$ & Chi-square & p-value \\
\hline \multicolumn{5}{|l|}{ Gender } \\
\hline Male & $85(75)$ & $28(25)$ & 37.25 & $<0.001$ \\
\hline Female & $7(19)$ & $30(81)$ & & \\
\hline \multicolumn{5}{|l|}{ Year of Education } \\
\hline First & $14(70)$ & $9(30)$ & 10.13 & 0.072 \\
\hline Second & $25(68)$ & $12(32)$ & & \\
\hline Third & $31(55)$ & $26(46)$ & & \\
\hline Fourth & $22(75)$ & $11(25)$ & & \\
\hline \multicolumn{5}{|l|}{ Smokeless Tobacco use } \\
\hline Yes & $30(100)$ & $0(0)$ & 23.64 & $<0.001$ \\
\hline No & $62(52)$ & $58(48)$ & & \\
\hline \multicolumn{5}{|l|}{ Family member use tobacco } \\
\hline Yes & $60(90)$ & $7(10)$ & 40.65 & $<0.001$ \\
\hline No & $32(39)$ & $51(61)$ & & \\
\hline \multicolumn{5}{|l|}{ Ever had dental check-up } \\
\hline Yes & $57(81)$ & $13(19)$ & 22.34 & $<0.001$ \\
\hline No & $35(44)$ & $45(56)$ & & \\
\hline
\end{tabular}

Table 3. Number of Cigarettes Smoked by Dental Students

\begin{tabular}{|c|c|}
\hline \begin{tabular}{c} 
Frequency of daily cigarette smoked \\
\hline$<10$
\end{tabular} & $\begin{array}{c}\text { Participants } \\
\mathbf{n}(\%)\end{array}$ \\
\hline \hline $11-20$ & $61(66.3)$ \\
\hline $21-30$ & $18(19.6)$ \\
\hline 31 or more & $5(5.4)$ \\
\hline Total & $8(8.7)$ \\
\hline
\end{tabular}

Table 4. Tobacco Use and Gingival Index Scores

\begin{tabular}{|c|c|c|c|}
\hline & Tobacco users & Tobacco Non-Users & P-value \\
\hline \hline Gingival index & $1.25 \pm 0.91$ & $0.39 \pm 0.63$ & $<0.001$ \\
\hline
\end{tabular}


Table 4 shows the mean GI score comparisons between smokers and non-smokers. There was a statistically significant higher GI scores among smokers compared to non-smokers.

\section{DISCUSSION}

This study found a high frequency of smoking among dental college students. It was more common among males as compared to females. The students who smoke had more regular dental checkups compared to those who didn't smoke.. There was a statistically significant difference between the total GI score among those who smoke and those who didn't. Other forms of tobacco use, such as smokeless tobacco were also found to be associated with smoking. These trends were more common among males.

We found similar results as reported by a study conducted in Saudi Arabia ${ }^{4}$. The high prevalence of tobacco use, both smoked and smokeless, among dental students in a dental college of Karachi reflects a number of reasons. Smoking is started at a younger age among Pakistani adolescents, before their admission to medical or dental colleges hence a good proportion of these students enter medical and dental colleges already using tobacco. Secondly the once in dental colleges and acquiring the knowledge regarding hazards to tobacco use, majority of the students don't quit its use reflecting the level of addiction and tobacco dependence.

\section{REFERENCES}

1. Xiang H, Wang Z, Stallones L, Yu S, Gimbel HW, Yang P. Cigarette smoking among medical college students in Wuhan, People's Republic of China. Preventive medicine. 1999;29:210-5.

2. Khan F, Husain S, Laeeq A, Awais A, Hussain S, Khan J. Smoking prevalence, knowledge and attitudes among medical students in Karachi, Pakistan. 2005.

3. Azab M, Khabour OF, Alzoubi KH, Anabtawi MM, Quttina M, Khader Y, et al. Exposure of pregnant women to waterpipe and cigarette smoke. Nicotine \& Tobacco Research. 2013;15:231-7.

4. Almas K, Al-Hawish A, Al-Khamis W. Oral hygiene practices, smoking habit, and self-perceived oral malodor among dental students. J Contemp Dent Pract. 2003;4:77-90.

5. Kaplan RM, Fang Z, Morgan G. Providers' advice concerning smoking cessation: Evidence from the Medical Expenditures Panel Survey. Prev Med. 2016;91:32-6.
The effect of smoking on the presence of gingivitis is reported by several studies ${ }^{12-14}$. The dental students have knowledge of oral hygiene and hazards of smoking, in spite of this fact this study found a high frequency of smokers among dental students.

The probable mechanism of causation might include decrease in blood flow to gingival tissue due to damaged blood vessels ${ }^{15}$. Furthermore, the tar in the cigarette smoke causes plaque to accumulate which increases the chances of periodontitis $^{16}$.

\section{CONCLUSION}

This study found high frequency of smoking among dental students and the gingival index score was higher among smokers as compared to non-smokers.

\section{RECOMMENDATIONS}

This situation is alarming as for students of dental health sciences, these students should be considered advocate of smoking cessation programs and role models for the community. It is recommended that health education programs should be implemented for the control and prevention of smoking and related dental hazards due to smoking.

6. Smith D, Leggat P. An international review of tobacco smoking among medical students. Journal of postgraduate medicine. 2007;53:55.

7. Omair A, Kazmi T, Alam S. Smoking prevalence and awareness about tobacco related diseases among medical students of Ziauddin Medical University. JPMA. 2002;52(389).

8. Grant BF. Age at smoking onset and its association with alcohol consumption and DSM-IV alcohol abuse and dependence: results from the National Longitudinal Alcohol Epidemiologic Survey. Journal of substance abuse. 1998;10:59-73.

9. Khuder SA, Dayal HH, Mutgi AB. Age at smoking onset and its effect on smoking cessation. Addictive behaviors. 1999;24:673-7.

10. Hussain SF, Moid I, Khan JA. Attitudes of Asian medical students towards smoking. Thorax. 1995;50:996-7.

11. King BA, Dube SR, Tynan MA. Current tobacco use among adults in the United States: findings from the 
National Adult Tobacco Survey. American journal of public health. 2012;102:e93-e100.

12. Al-Bayaty FH, Baharuddin N, Abdulla MA, Ali HM, Arkilla MB, ALBayaty MF. The influence of cigarette smoking on gingival bleeding and serum concentrations of haptoglobin and alpha 1-antitrypsin. BioMed research international. 2013;2013.

13. Alexander A. The relationship between tobacco smoking calculus and plaque accumulation and gingivitis. Dental health. 1969;9:6-9.

14. Allam E, Zhang W, Zheng C, Gregory RL, Windsor LJ. Smoking and oral health. Cigarette Smoke Toxicity:
Linking Individual Chemicals to Human Diseases. 2011:257-80.

15. Müller HP, Stadermann S, Heinecke A. Longitudinal association between plaque and gingival bleeding in smokers and non-smokers. Journal of clinical periodontology. 2002;29:287-94.

16. Naderi NJ, Semyari H, Elahinia Z. The Impact of Smoking on Gingiva: a Histopathological Study. Iranian journal of pathology. 2015;10:214. 